\title{
Plasma C-terminal pro-endothelin-1 and the natriuretic pro-peptides NT-proBNP and MR-proANP in very preterm infants with patent ductus arteriosus
}

\author{
Letzner, J ; Berger, F ; Schwabe, S ; Benzing, J ; Morgenthaler, N G ; Bucher, H U ; Bührer, C ; \\ Arlettaz, R ; Wellmann, S
}

\begin{abstract}
BACKGROUND: In very preterm infants, clinical decision-making, such as closing a patent ductus arteriosus (PDA), may be aided by measuring circulating natriuretic and endothelial pro-peptides. OBJECTIVES: To investigate the association between perinatal characteristics, PDA echocardiography and plasma concentrations of stable pro-peptides of B-type natriuretic peptide (NT-proBNP), atrial natriuretic peptide (MR-proANP) and endothelin-1 (CT-proET-1). METHODS: A prospective, crosssectional, single-center study was performed in 66 infants who were less than 32 weeks of gestational age. Pro-peptide concentrations were determined at birth and at day 2-3 of life. RESULTS: Plasma concentrations of all 3 pro-peptides increased on average 2- to 5-fold from birth to day 2-3 of life. NTproBNP and MR-proANP were closely related at birth and at day 2-3 (Rs 0.902 and 0.897, respectively, $\mathrm{p}<0.001$ ), whereas CT-proET-1 was related to NT-proBNP and MR-proANP at birth (Rs 0.478 and 0.460 , respectively, $\mathrm{p}<0.001$ ) but not at day $2-3$. Birth weight was negatively related to all 3 pro-peptides at birth $(\mathrm{p}<0.01)$; however, preeclampsia and compromised placental perfusion were associated with elevated NT-proBNP and MR-proANP concentrations at birth. At day 2-3, MR-proANP and NTproBNP correlated significantly with the ductal diameter ( $\operatorname{Rs} 0.416$ and 0.415 , respectively, both $\mathrm{p}=$ 0.011), whereas CT-proET-1 correlated with the left atrium/aorta ratio ( $\operatorname{Rs} 0.506, p=0.027)$. CTproET-1 was elevated in infants with treated compared to untreated PDA [median (5-95\% range) 388 (272-723) vs. $303(152-422) \mathrm{pmol} / \mathrm{l}, \mathrm{p}=0.011]$, but not NT-proBNP or MR-proANP. CONCLUSION: CT-proET-1 is a promising predictor in determining the need for PDA intervention.
\end{abstract}

DOI: https://doi.org/10.1159/000330411

Posted at the Zurich Open Repository and Archive, University of Zurich

ZORA URL: https://doi.org/10.5167/uzh-70600

Journal Article

Published Version

Originally published at:

Letzner, J; Berger, F; Schwabe, S; Benzing, J; Morgenthaler, N G; Bucher, H U; Bührer, C; Arlettaz, R; Wellmann, S (2012). Plasma C-terminal pro-endothelin-1 and the natriuretic pro-peptides NT-proBNP and MR-proANP in very preterm infants with patent ductus arteriosus. Neonatology, 101(2):116-124.

DOI: https://doi.org/10.1159/000330411 


\title{
Plasma C-Terminal Pro-Endothelin-1 and the Natriuretic Pro-Peptides NT-proBNP and MR-proANP in Very Preterm Infants with Patent Ductus Arteriosus
}

\author{
Julia Letzner $^{\mathrm{a}} \quad$ Florian Berger $^{\mathrm{a}} \quad$ Sarah Schwabe $^{\mathrm{a}} \quad$ Jörg Benzing ${ }^{\mathrm{b}}$ \\ Nils G. Morgenthaler ${ }^{c}$ Hans Ulrich Bucher ${ }^{a}$ Christoph Bührer ${ }^{d}$ \\ Romaine Arlettaz ${ }^{a}$ Sven Wellmann ${ }^{a}$ b \\ a Division of Neonatology, University Hospital Zurich, Zurich, 'b Division of Neonatology, University Children's \\ Hospital Basel, Basel, Switzerland; ' $R e s e a r c h$ Department, BRAHMS Biomarkers, Thermo Fisher Scientific, \\ Hennigsdorf, and d Department of Neonatology, Charité University Medical Center, Berlin, Germany
}

\section{Key Words}

Patent ductus arteriosus • Preterm infant - Endothelin-1 . B-type natriuretic peptide $\cdot$ Atrial natriuretic peptide $\cdot$

Biomarker $\cdot$ Birth

\begin{abstract}
Background: In very preterm infants, clinical decision-making, such as closing a patent ductus arteriosus (PDA), may be aided by measuring circulating natriuretic and endothelial pro-peptides. Objectives: To investigate the association between perinatal characteristics, PDA echocardiography and plasma concentrations of stable pro-peptides of B-type natriuretic peptide (NT-proBNP), atrial natriuretic peptide (MRproANP) and endothelin-1 (CT-proET-1). Methods: A prospective, cross-sectional, single-center study was performed in 66 infants who were less than 32 weeks of gestational age. Pro-peptide concentrations were determined at birth and at day 2-3 of life. Results: Plasma concentrations of all 3 propeptides increased on average 2- to 5-fold from birth to day 2-3 of life. NT-proBNP and MR-proANP were closely related
\end{abstract}

at birth and at day 2-3 (Rs 0.902 and 0.897 , respectively, $\mathrm{p}<$ 0.001), whereas CT-proET-1 was related to NT-proBNP and MR-proANP at birth (Rs 0.478 and 0.460 , respectively, p < 0.001 ) but not at day $2-3$. Birth weight was negatively related to all 3 pro-peptides at birth $(p<0.01)$; however, preeclampsia and compromised placental perfusion were associated with elevated NT-proBNP and MR-proANP concentrations at birth. At day 2-3, MR-proANP and NT-proBNP correlated significantly with the ductal diameter (Rs 0.416 and 0.415 , respectively, both $p=0.011$ ), whereas CT-proET-1 correlated with the left atrium/aorta ratio (Rs $0.506, p=0.027$ ). CT-proET-1 was elevated in infants with treated compared to untreated PDA [median (5-95\% range) 388 (272-723) vs. 303 (152-422) pmol/l, $\mathrm{p}=0.011]$, but not NT-proBNP or MR-proANP. Conclusion: CT-proET-1 is a promising predictor in determining the need for PDA intervention.

Copyright $\odot 2011$ S. Karger AG, Basel

R.A. and S.W. contributed equally to this work.

\section{KARGER}

Fax +41613061234 E-Mail karger@karger.ch www.karger.com
(C) 2011 S. Karger AG, Base

$1661-7800 / 12 / 1012-0116 \$ 38.00 / 0$

Accessible online at:

www.karger.com/neo
Dr. Sven Wellmann

Klinik für Neonatologie, Universitätsspital Zürich

Frauenklinikstr. 10

CH-8091 Zurich (Switzerland)

Tel. +41 44255 5340, E-Mail sven.wellmann@usz.ch 


\section{Introduction}

Patency of the ductus arteriosus (DA) is common in preterm infants. Aortopulmonary shunting through the patent ductus arteriosus (PDA) augments pulmonary blood flow followed by an increase in myocardial load and a decrease in systemic blood pressure [1-3]. The association of these hemodynamic alterations with shortand long-term morbidities remains a matter of controversy. While echocardiography is the standard procedure to detect PDA, it is not always available in all NICUs. Moreover, a decision to treat a PDA is complex and may be aided by other diagnostic measures, such as chest Xray [4] and circulating plasma biomarkers [1]. The inability of echocardiography to accurately differentiate the pathological DA from the innocent DA [5] supports the use of putative biomarkers that integrate hemodynamic consequences over time [1]. Hemodynamic consequences of PDA, such as ductal steal from vital organs compromising the cerebral and/or enteric circulations, are more important than the stretch on the left atrium/aorta ratio (LA/Ao ratio) [6]. Nonselective treatment of all very preterm infants with inhibitors of prostaglandin synthesis is not justified due to the side effects, costs and lack of longterm benefit $[1,7]$.

The natriuretic peptides B-type natriuretic peptide (BNP) and atrial natriuretic peptide (ANP) are released from distended and stressed myocardium in response to volume and pressure load. Several studies have demonstrated increased concentrations of BNP [8] and its stable by-product, N-Terminal-proBNP (NT-proBNP) [9], in infants with PDA. Another study has also found increased concentrations of the stable by-product of ANP (proANP) in preterm infants with PDA [10]. So far, a direct comparison of proANP and NT-proBNP has never been performed.

The release of natriuretic peptides by the distended myocardium is an adaptive mechanism that occurs in response to a hemodynamically significant PDA to reduce volume load. All endothelial cells have the capability to synthesize endothelin-1 (ET-1) and release stored ET-1 in response to various stressors [11]. This endothelial vasoconstrictor may be released from pulmonary vessels in response to increased pulmonary blood flow secondary to the PDA-mediated left-to-right shunting [1]. Urinary excretion of ET-1, the main endothelial vasoconstrictor, has been found to diminish after PDA closure $[12,13]$. Circulating ET-1 concentrations can be reliably assessed by measuring the stable by-product C-terminal proET-1 (CT-proET-1) [14]. Reference values have been established in term healthy newborn infants [15], but the impact of prematurity has not yet been investigated.

In this cross-sectional prospective study, we measured MR-proANP, NT-proBNP and CT-proET-1 in plasma samples of 66 very preterm infants obtained from the umbilical cord and repeat samples obtained at 2-3 days of life. The findings were related to indices of prematurity and ductal patency.

\section{Materials and Methods}

This blinded, prospective, cross-sectional study included 66 very preterm infants born at the University Hospital of Zurich between February and December 2010. The study participants were enrolled after obtaining informed written consent from the parents. The institutional review board in Zurich approved this study. Infants were eligible if born before 32 weeks of gestational age. Gestational age was determined by a combination of the first day of the mother's last menstrual period and an early ultrasound scan in the first trimester. Within the study period of 11 months, 122 infants were born at the University Hospital of Zurich before 32 weeks of gestational age. Fifteen of the infants died within the first hours of life before admission to the NICU due to extreme prematurity (23 and 24 weeks of gestational age, $n=9$ ), severe hydrops $(n=2)$ and major congenital abnormalities $(n=4)$. Of the 103 infants admitted to the NICU, 2 were excluded because of major congenital abnormalities, including structural heart disease. Clinical data were recorded as described previously [16]. None of the infants within the study group had a ventricular septum defect, atrial septum defect or developed cystic periventricular leukomalacia. All infants who were endotracheally intubated and ventilated had exogenous surfactant administration. Placentas were histologically examined for signs of chorioamnionitis and altered placental perfusion capacity.

Venous blood samples were drawn from the umbilical cord at the time of delivery and at 2-3 days of life, collected in EDTA tubes, and handled as described previously [17]. Blood sampling on day 2-3 was performed in parallel with echocardiography (within 0-4h). Due to limitations in blood volume, the measurements were performed in the following order: NT-proBNP, MRproANP and CT-proET-1. Pro-peptides were each measured in a single batch with BRAHMS KRYPTOR automated immunofluorescent assays (BRAHMS Biomarkers, Thermo Fisher Scientific, Hennigsdorf, Germany). Both fully automated assays are based on the sandwich immunoassays described in detail elsewhere (for MR-proANP [18] and CT-proET1 [14]), and have comparable precision and lower detection limits. NT-proBNP was analyzed using the Roche assay [19].

Echocardiographic measurements were performed in parallel with blood collections at day 2-3 of life by a single sonographer (R.A.) using the Siemens Acuson Sequoia Ultrasound machine and a $10 \mathrm{v} 4$ cardiology multifrequency probe. Two-dimensional, M-mode, pulse and color flow Doppler imaging were performed. The indication for ductus intervention was based on the presence of the following previously established criteria [20]: presence of PDA with left-to-right shunting, narrowest ductal diameter $\geq 1.5$ 
Table 1. Patient characteristics

\begin{tabular}{|c|c|c|c|}
\hline & \multicolumn{2}{|c|}{ PDA study group $(n=66)$} & \multirow[t]{2}{*}{$\mathrm{p}$} \\
\hline & intervention $(\mathrm{n}=25)$ & control $(n=41)$ & \\
\hline \multicolumn{4}{|l|}{ Maternal characteristics } \\
\hline Signs of infection at delivery & $5(20)$ & $13(32)$ & $>0.1$ \\
\hline Preeclampsia & $12(48)$ & $12(29)$ & $>0.1$ \\
\hline Vaginal/abdominal delivery & $1 / 24(4 / 96)$ & $6 / 35(15 / 85)$ & $>0.1$ \\
\hline \multicolumn{4}{|l|}{ Fetal characteristics } \\
\hline Small for gestational age, $<5$ th percentile & $6(24)$ & $3(7)$ & 0.057 \\
\hline Suspect fetal heart rate just prior to delivery & $9(36)$ & $12(29)$ & $>0.1$ \\
\hline Antenatal steroids, complete & $22(88)$ & $5(88)$ & $>0.1$ \\
\hline \multicolumn{4}{|l|}{ Placenta } \\
\hline Compromised placental perfusion & $14(56)$ & $16(39)$ & $>0.1$ \\
\hline Chorioamnionitis & $3(12)$ & $12(29)$ & 0.097 \\
\hline \multicolumn{4}{|l|}{ Neonatal characteristics } \\
\hline Gestational age, week & $28(24.7-31.6)$ & $30.7(26.2-31.9)$ & $<0.001$ \\
\hline Birth weight, $g$ & $960(573-1,797)$ & $1,400(806-2,011)$ & $<0.001$ \\
\hline Arterial cord blood $\mathrm{pH}$ & $7.32(7.17-7.43)$ & $7.32(7.07-7.40)$ & $>0.1$ \\
\hline Apgar score at $5 \mathrm{~min}$ & $7(2-9)$ & $7(2-9)$ & $>0.1$ \\
\hline Apgar score at $10 \mathrm{~min}$ & $8(3-10)$ & $9(3-10)$ & $>0.1$ \\
\hline Male gender & $12(48)$ & $24(58)$ & $>0.1$ \\
\hline \multicolumn{4}{|l|}{ Postnatal course until day 3 of life } \\
\hline Positive pressure ventilation & $14(56)$ & $12(29)$ & 0.032 \\
\hline Nasal CPAP & $24(96)$ & $23(56)$ & $<0.01$ \\
\hline Intraventricular hemorrhage & $3(12)$ & $4(10)$ & $>0.1$ \\
\hline Sepsis with positive blood culture & $3(12)$ & $1(2)$ & $>0.1$ \\
\hline Postnatal course until discharge & $3(12)$ & $1(2)$ & $>0.1$ \\
\hline Bronchopulmonary dysplasia & $2(8)$ & $1(2)$ & $>0.1$ \\
\hline Retinopathy of prematurity $\left(>^{\circ} \mathrm{I}\right)$ & $2(8)$ & $0(0)$ & 0.066 \\
\hline Necrotizing enterocolitis ( $\left.>^{\circ} \mathrm{IIa}\right)$ & $0(0)$ & $1(2)$ & $>0.1$ \\
\hline Death & $6(24)$ & $5(12)$ & $>0.1$ \\
\hline \multicolumn{4}{|l|}{ Echocardiographic assessment } \\
\hline LA/Ao ratio & $1.4(1.1-2.2)$ & $1.2(0.7-2.1)$ & 0.013 \\
\hline Narrowest ductal diameter & $1.8(1.4-2.8)$ & $0.0(0.0-2.8)$ & $<0.001$ \\
\hline
\end{tabular}

$\mathrm{mm}$ and $\mathrm{LA} / \mathrm{Ao}$ ratio $\geq 1.5$, and diastolic retrograde flow in the postductal descending aorta. Treatment of PDA using indomethacin $(0.6 \mathrm{mg} / \mathrm{kg}$ in 3 or 6 doses at intervals of 12 or $24 \mathrm{~h}$, respectively, depending on clinical considerations) commenced when indicated immediately after echocardiographic measurement. Surgical closure was performed when PDA remained despite three courses of indomethacin and when weaning from respiratory support failed $(n=3)$. Prophylactic indomethacin was not used during the study period.

Statistical analyses were made using PASW 18.0 (SPSS Inc., Chicago, Ill., USA) in a strictly nonparametric fashion. Continuous variables were given as a median (5-95\% range). Additionally, Spearman's rank order correlation coefficients were calculated, and either a Mann-Whitney U test, Kruskal-Wallis or Fisher's exact test was employed as appropriate. $\mathrm{p}<0.05$ was considered significant.

\section{Results}

\section{Patients}

Patient characteristics are given in table 1. When compared to the infants who did not undergo PDA treatment, the infants who underwent PDA treatment had a lower gestational age, lower birth weight and more respiratory support.

Concentrations of Circulating Pro-Peptides at Birth and Day 2-3 of Life

Plasma concentrations of all 3 pro-peptides [median (5-95\% range)] at birth and at day $2-3$ in the total study population of 66 very preterm infants are given in ta- 
Table 2. Plasma concentrations of pro-peptides at birth and at day $2-3$ according PDA stratification

\begin{tabular}{|c|c|c|c|c|}
\hline & \multicolumn{2}{|l|}{ Birth } & \multicolumn{2}{|l|}{ Day 2-3 } \\
\hline & control & intervention & control & intervention \\
\hline NT-proBNP, mg/ml & $\mathrm{n}=31$ & $\mathrm{n}=20$ & $\mathrm{n}=21$ & $\mathrm{n}=19$ \\
\hline Median & 1,908 & 3,878 & 8,714 & 12,030 \\
\hline $5-95 \%$ range & $558-16,858$ & $790-14,708$ & $1,210-35,000$ & $3,198-35,000$ \\
\hline $\mathrm{p}$ & \multicolumn{2}{|c|}{0.095} & \multicolumn{2}{|c|}{$>0.1$} \\
\hline MR-proANP, pmol/l & $\mathrm{n}=33$ & $\mathrm{n}=20$ & $\mathrm{n}=21$ & $\mathrm{n}=19$ \\
\hline Median & 535 & 829 & 1,201 & 1,415 \\
\hline $5-95 \%$ range & $265-1,360$ & $339-2,494$ & $357-4,132$ & $623-2,854$ \\
\hline $\mathrm{p}$ & \multicolumn{2}{|c|}{0.016} & \multicolumn{2}{|c|}{$>0.1$} \\
\hline CT-proET-1, pmol/1 & $\mathrm{n}=32$ & $\mathrm{n}=20$ & $\mathrm{n}=9$ & $\mathrm{n}=11$ \\
\hline Median & 160 & 176 & 303 & 388 \\
\hline $5-95 \%$ range & $82-308$ & $70-326$ & $152-422$ & $272-727$ \\
\hline $\mathrm{p}$ & \multicolumn{2}{|c|}{$>0.1$} & \multicolumn{2}{|c|}{0.011} \\
\hline
\end{tabular}

ble 2. Changes from birth to day 2-3 are shown in figure 1 (only infants with paired samples). Subdividing these data as given in table 2 according to PDA stratification showed that the increase of MR-proANP, NT-proBNP and CT-proET-1 from birth to day 2-3 was significant $(p<0.001)$ for each of the pro-peptides in the intervention (PDA treatment) and in the control group (no PDA treatment).

\section{Relationship between Circulating Pro-Peptides}

At birth, we noted a close correlation between MRproANP and NT-proBNP concentrations (Rs 0.902, $\mathrm{p}<$ $0.001, \mathrm{n}=51$; fig. $2 \mathrm{a}$ ) within the umbilical cord blood samples. A moderate correlation between CT-proET-1 and MR-proANP (Rs 0.460, $\mathrm{p}<0.001, \mathrm{n}=52$ ) as well as CT-proET-1 and NT-proBNP (Rs 0.478, $\mathrm{p}<0.001, \mathrm{n}=50$ ) was also noted within the umbilical cord samples. Within the samples from day 2-3 of life, there was again a close correlation between MR-proANP and NT-proBNP (Rs $0.897, \mathrm{p}<0.001, \mathrm{n}=39$; fig. $2 \mathrm{~b}$ ), but no correlation between CT-proET-1 and MR-proANP or between CT-proET-1 and NT-proBNP. No correlations were found between umbilical cord plasma and day $2-3$ concentrations of MR-proANP, NT-proBNP and CT-proET-1.

\section{Influence of Infants' Birth Parameters on Pro-Peptide} Concentrations

While birth weight correlated negatively with umbilical cord blood concentrations of MR-proANP (Rs -0.564, $\mathrm{p}<0.001, \mathrm{n}=54)$, NT-proBNP (Rs -0.492, $\mathrm{p}<0.001, \mathrm{n}=$ 51) and CT-proET-1 (Rs $-0.345, \mathrm{p}=0.012, \mathrm{n}=52)$, there was only a weak correlation between gestational age and MR-proANP concentrations at birth (Rs -0.377, $\mathrm{p}=$ $0.005, \mathrm{n}=54)$. In addition, MR-proANP, NT-proBNP and CT-proET-1 concentrations at birth were higher in infants who were small for their gestational age (Rs -0.398 , $\mathrm{p}=0.003, \mathrm{n}=54 ; \mathrm{Rs}-0.424, \mathrm{p}=0.002, \mathrm{n}=51$; Rs -0.420 , $\mathrm{p}=0.002, \mathrm{n}=52$, respectively). Day $2-3$ concentrations of MR-proANP, NT-proBNP and CT-proET-1 were not correlated with birth weight or with gestational age. Gender was not associated with any differences in pro-peptide concentrations at birth or day 2-3.

Weak negative correlations were noted between umbilical cord blood $\mathrm{pH}$ and umbilical cord blood concentrations of MR-proANP and NT-proBNP (Rs -0.337, p = $0.016, \mathrm{n}=51$, and $\mathrm{Rs}-0.336, \mathrm{p}=0.019, \mathrm{n}=48$, respectively). Correlations were also noted between the 5-min Apgar scores and MR-proANP and NT-proBNP (Rs $-0.409, \mathrm{p}=0.002, \mathrm{n}=54$, and Rs $-0.331, \mathrm{p}=0.018, \mathrm{n}=51$, respectively).

\section{Influence of Parameters before Delivery on Circulating} Pro-Peptide Concentrations

Among the various maternal factors recorded in the present study (infection immediately prior to delivery, preeclampsia, suspect fetal heart rate tracings and administration of antenatal steroids), only preeclampsia was associated with higher concentrations of MR-proANP and NT-proBNP [MR-proANP: median 799 (5$95 \%$ range: $373-2,414)$ vs. $503(263-1,711], \mathrm{p}=0.003$; NTproBNP: $4,403(1,103-1,4946)$ vs. $1,760(568-15,547), \mathrm{p}=$ $0.011]$. 


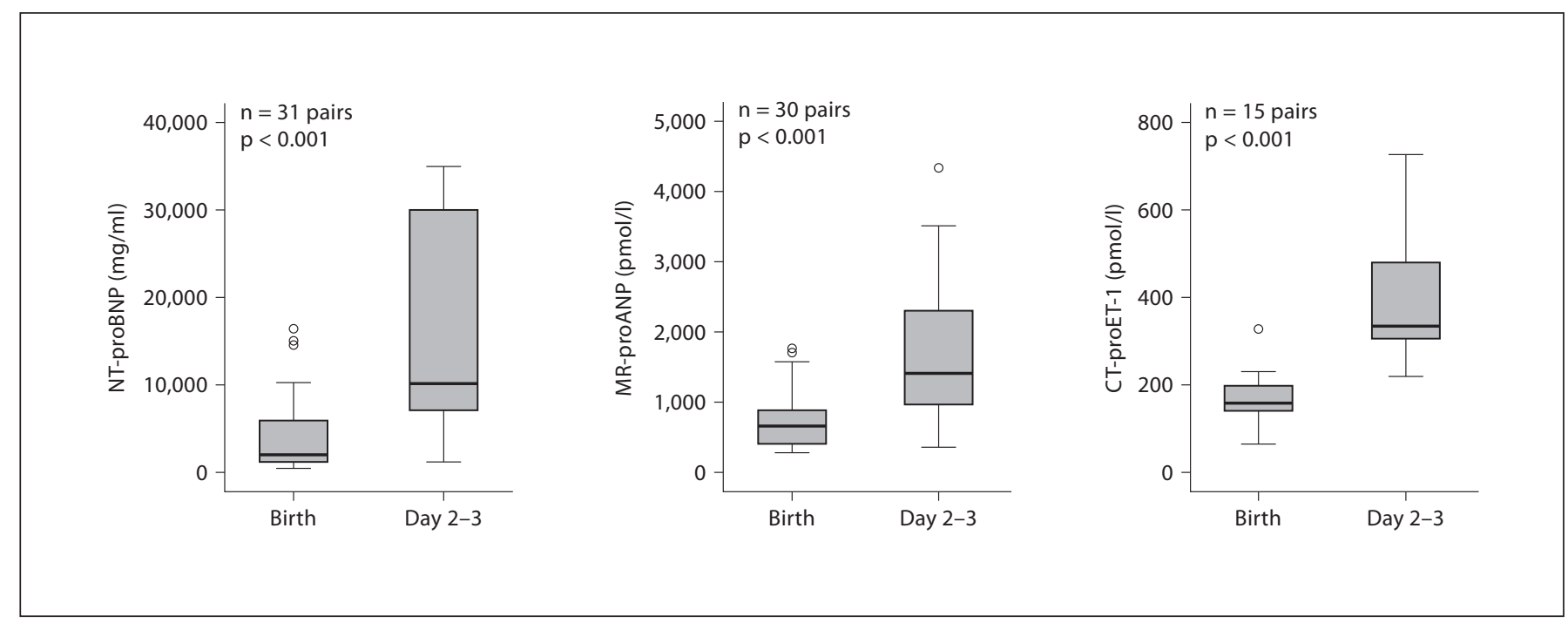

Fig. 1. Plasma concentrations of pro-peptides in paired samples at birth and day $2-3$ of life. NT-proBNP, MRproANP and CT-proET1 plasma concentrations are presented as box (interquartile range) and whisker (5-95\% range) plots. Outliers are marked by circles.

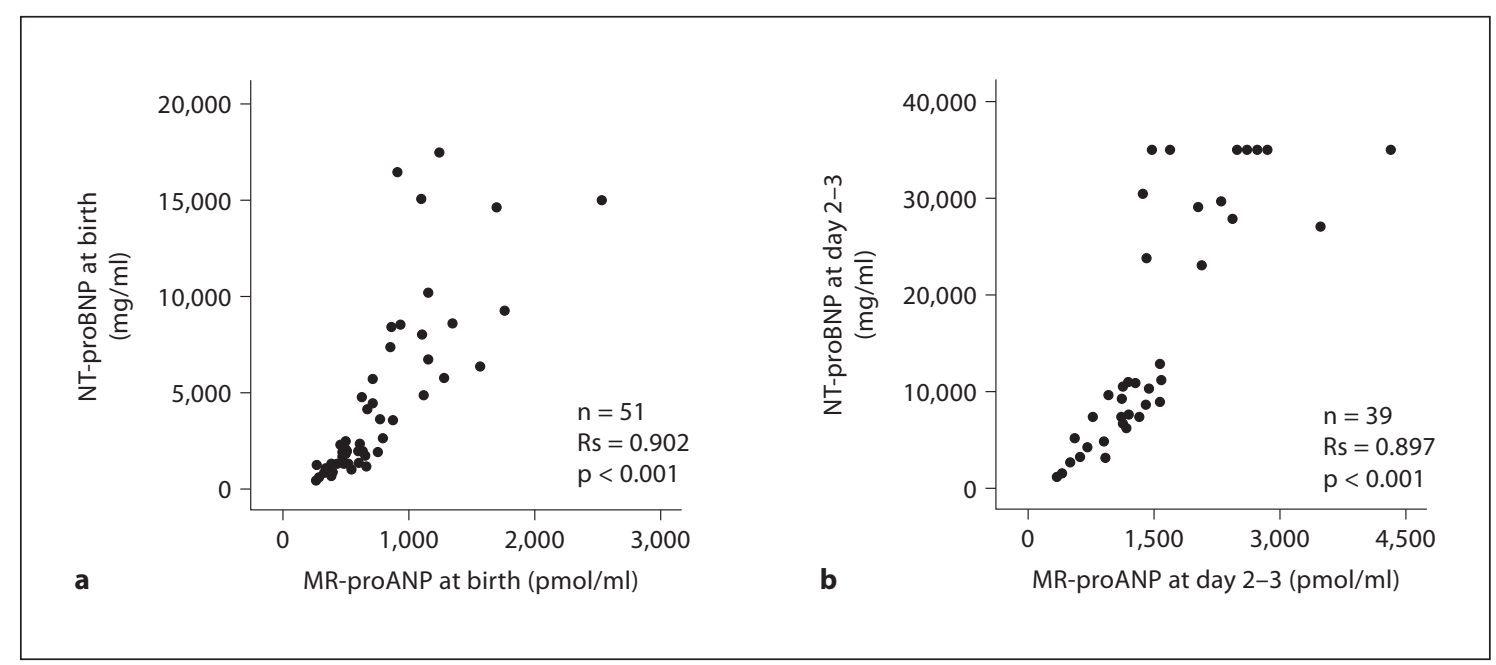

Fig. 2. Correlation of NT-proBNP and MR-proANP plasma concentrations at birth (a) and at day 2-3 of life (b). Data are presented as scatter plots. Patient number (n), Spearman's rank order correlation coefficients (Rs) and level of significance (p) are given.

Placenta Histology and Pro-Peptide Concentrations While chorioamnionitis did not influence pro-peptide concentrations, supporting the above-mentioned finding that there was no association between maternal infection and pro-peptide concentrations, there was a significant effect of altered placental perfusion capacity. Infants suffering from compromised placental perfusion had elevat- ed concentrations of MR-proANP, NT-proBNP and CTproET-1 in umbilical cord blood compared to the controls [MR-pro-ANP: 860 (304-1,340] vs. 505 (262-2,031), p = 0.013 ; NT-proBNP: $4,756(639-15,062)$ vs. 1,908 (59515,546), $\mathrm{p}=0.042$; CT-proET-1: 192 (90-290) vs. 149 (67308), $\mathrm{p}=0.01]$. 


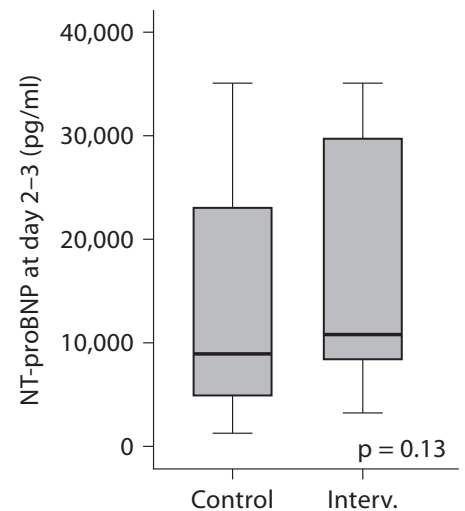

a

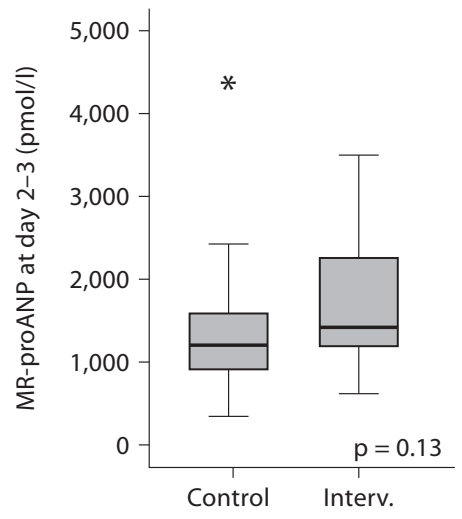

b

PDA treatment

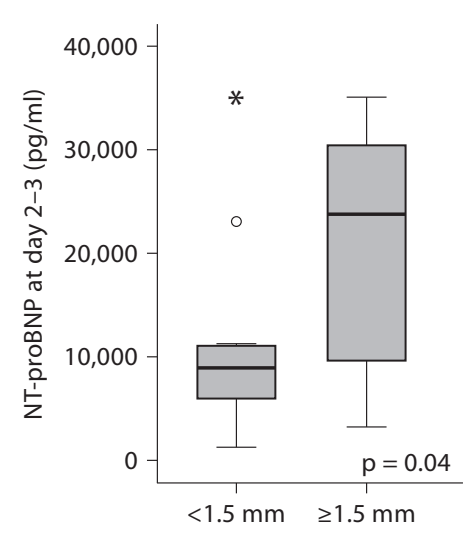

d
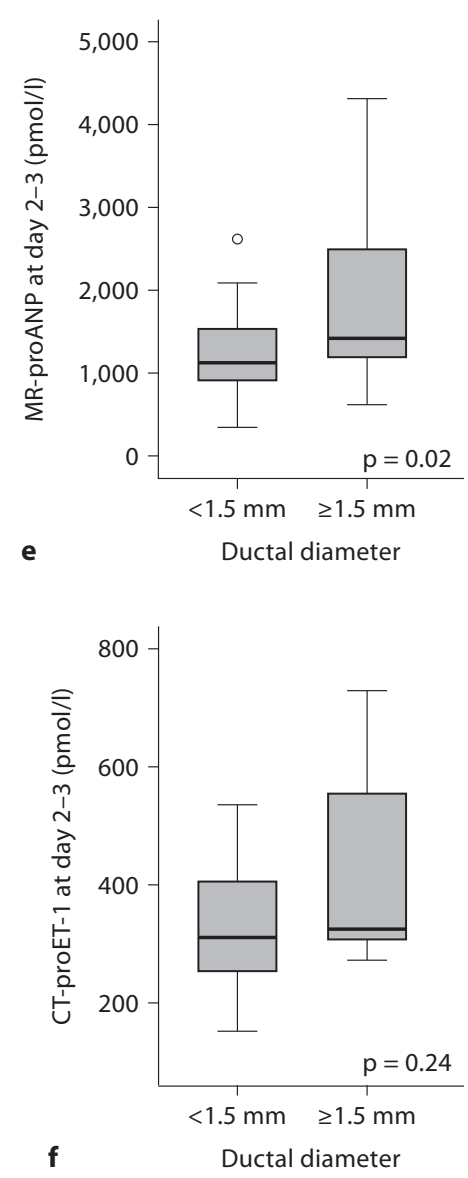

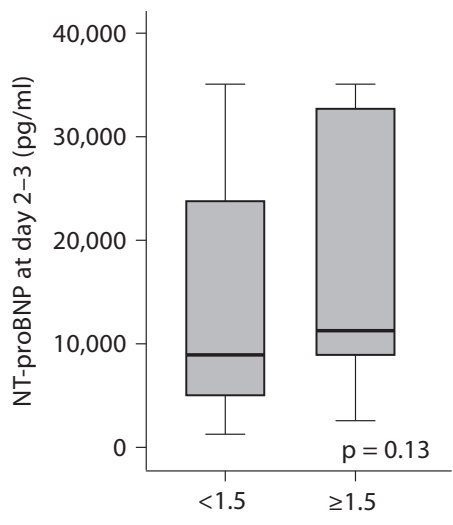

g

LA/Ao ratio

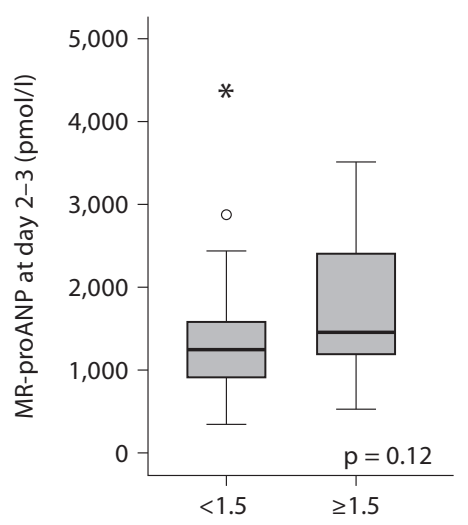

h

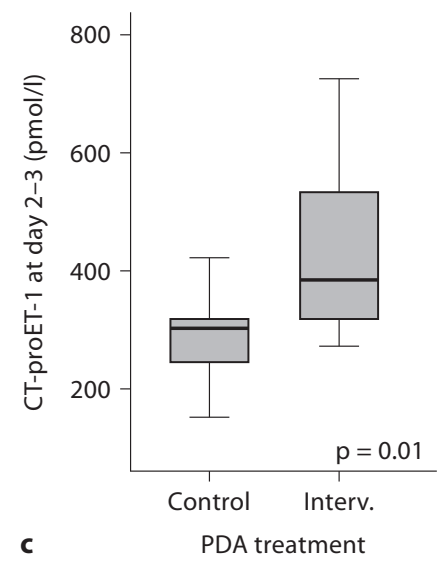

c

PDA treatment

Fig. 3. Plasma concentrations of pro-peptides at day 2-3 of life according to PDA study groups and echocardiographic indices. Pro-peptide plasma concentrations of NT-proBNP, MR-proANP and CT-proET-1 are given with respect to PDA treatment groups $(\mathbf{a}-\mathbf{c})$, ductal diameter $(\mathbf{d}-\mathbf{f})$ and LA/Ao ratio $(\mathbf{g}-\mathbf{i})$, as indicated. Concentrations are presented as box (interquartile range) and whisker (5-95\% range) plots. Outliers are marked by circles and asterisks. 


\section{Relation of Postnatal Factors and Pro-Peptide Concentrations}

Infants receiving ventilator support in the first days of life (recorded until blood samples at day 2-3 were drawn) had significantly higher concentrations of MR-proANP and NT-proBNP in umbilical cord blood compared to the infants without ventilatory support [MR-proANP: 869 $(370-1,755)$ vs. $507(263-1,633), \mathrm{p}<0.001, \mathrm{n}=54$; NTproBNP 5,691 $(763-16,308)$ vs. $1,711(548-16,084), \mathrm{p}=$ $0.003, \mathrm{n}=51$. At day $2-3$, only CT-proET-1 levels were higher in infants receiving ventilator support in the first days of life [428 (265-712) vs. 303 (152-382), p = 0.002, $\mathrm{n}=20]$.

The infant variables that showed no relation to the concentrations of pro-peptides at birth or at day 2-3 were as follows: intraventricular hemorrhage, sepsis, bronchopulmonary dysplasia, retinopathy of prematurity, necrotizing enterocolitis and death.

\section{Pro-Peptide Concentrations and PDA}

Infants subjected to PDA treatment (see Materials and Methods for criteria) had significantly higher CT-proET-1 concentrations in day 2-3 blood samples. MR-proANP and NT-proBNP concentrations were also elevated, but not in a statistically significant fashion (fig. 3). MRproANP and NT-proBNP concentrations at day $2-3$ were significantly higher in infants with the ductal diameter $\geq 1.5 \mathrm{~mm}$ (fig. 3). In addition, MR-proANP and NTproBNP concentrations at day 2-3 correlated significantly with ductal diameter (Rs 0.416 and 0.415 , both $\mathrm{p}=$ 0.011, respectively), whereas CT-proET-1 concentrations showed no significance regarding difference and correlation. In contrast, CT-proET-1 concentrations at day 2-3 were significantly higher in infants with LA/Ao ratios $\geq 1.5$ (fig. 3), whereas MR-proANP and NT-proBNP only showed a trend towards higher concentrations. In addition, CT-proET-1 and NT-proBNP concentrations at day 2-3 correlated significantly with the LA/Ao ratio (Rs $0.506, \mathrm{p}=0.027$, and Rs 0.335, $\mathrm{p}=0.043$, respectively), whereas the association between the LA/Ao ratio and MR-proANP concentrations failed to reach statistical significance (Rs $0.319, \mathrm{p}=0.055$ ).

\section{Discussion}

The definition of a hemodynamically significant PDA and the use of medical and surgical procedures is an ongoing debate in neonatology [21]. Echocardiography is the most important testing method, but additional infor- mation is warranted to guide clinical decision-making. Plasma biomarkers may assist this process. We present data on the plasma concentrations of MR-proANP, NTproBNP and CT-proET-1 at birth and after 2-3 days of postnatal adaptation in preterm infants born more than 8 weeks before the expected date of delivery.

The 3 pro-peptides increased from birth to day 2-3 of life alongside the infant transition from fetal to postnatal circulation (fig 1). Subdividing these data according to PDA stratification showed that this increase with postnatal transition occurred independently of PDA evolution (table 2). This supports the previous findings of natriuretic peptides or the respective pro-peptides in infants born at term $[22,23]$. With respect to every aspect examined in this study, MR-proANP and NT-proBNP displayed a close correlation at birth as well as at day 2-3 (fig 2), including echocardiographical parameters (fig 3). Our study adds ET-1 to the list of peptides with a physiological role in the perinatal circulatory adaptation that occurs in the fetal-to-neonatal transition period.

CT-proET-1 concentrations in very preterm infants at birth (median 165, range 65-328 pmol/l) and at day 2-3 of life $(322,152-727 \mathrm{pmol} / \mathrm{l})$ were significantly elevated compared to published umbilical cord blood reference values for healthy infants born at term $(72,39-115$ pmol/l) [15] and venous blood samples from healthy adults $(44,11-77 \mathrm{pmol} / \mathrm{l})$ [14]. The high circulating CTproET-1 concentrations measured in very preterm infants on day 2-3 of life have been described previously only in critically ill adults suffering from severe sepsis or heart failure [14, 24, 25]. We failed to find any association between signs of infection (maternal or placental) and MR-proANP, NT-proBNP or CT-proET-1 concentrations in umbilical cord blood or in blood samples drawn at day 2-3 of life.

Although the number of preterm infants in this study was small, our data hint to a possible role for CT-proET-1 in estimating the hemodynamic significance of a PDA. While concentrations at day 2-3 of both natriuretic propeptides correlated with ductal diameter, CT-proET-1 concentrations correlated with the LA:Ao ratio. Additionally, CT-proET-1 was significantly elevated in infants who were subsequently chosen to undergo attempts at PDA closure. The limited number of patients may explain the lack of power that MR-proANP and NTproBNP have to predict or indicate hemodynamic significance of PDA (fig. 3a, b). The only published data on ET-1 concentrations in the urine of preterm infants showed a decrease with the pharmacological closure of PDA $[12,13]$. 
NT-proBNP and MR-proANP reflect the myocardial load in response to aortopulmonary shunting through the PDA. CT-proET-1 may reflect the pulmovascular burden caused by increased pulmonary blood flow. The natriuretic peptides (ANP and BNP) and ET- 1 are counteractive, and a certain balance between these peptides may be important. Natriuretic peptides are potent pulmonary vasodilators, whereas ET-1 is a vasoconstrictor. Further studies will focus on this particular balance and investigate how CT-proET-1 plasma concentrations correlate with the echocardiographic indices of pulmonary vasculature resistance.

In conclusion, CT-proET-1 is a promising predictor in determining the need for PDA intervention as it indicates additional information exceeding that of the natriuretic pro-peptides. Because the present study was only exploratory, the clinical usefulness of determining CT-proET-1 remains to be determined in larger prospective trials. It must be proven whether assessing CT-proET-1 alone is sufficient to predict the need for PDA intervention. Additionally, it must be proven if a combination of CT-proET-1 and natriuretic pro-peptides or rather a multimodal approach, including plasma biomarkers, echocardiography and individual physiological patient characteristics, is beneficial to accurately differentiate pathological DA from innocent DA.

\section{Acknowledgements}

We are grateful to Prof. Rosmarie Caduff, Institute of Pathology, University Hospital Zurich, for histological examination of placentae. S.W. was supported by a Swiss National Science Foundation Career Award for Medical Scientists (33CM30-124101). The study was funded by in-house grants from the Division of Neonatology, University Hospital Zurich, Switzerland.

\section{Disclosure Statement}

N.G.M. is employed by BRAHMS Biomarkers, the manufacturer of the MR-proADM assay for which it owns patent rights (BRAHMS Biomarkers, part of Thermo Fisher Scientific, Hennigsdorf, Germany). The company had no influence on the design of the study or on the writing of the manuscript. The remaining authors have nothing to declare.

\section{References}

1 Hamrick SE, Hansmann G: Patent ductus arteriosus of the preterm infant. Pediatrics 2010;125:1020-1030.

2 Obladen M: History of the ductus arteriosus: 1 . Anatomy and spontaneous closure. Neonatology 2011;99:83-89.

3 Obladen M: History of the ductus arteriosus: 2. Persisting patency in the preterm infant. Neonatology 2011;99:163-169.

4 Strauss T, Pessach I, Jacoby E, SchushanEisen I, Mazkereth R, Kuint J: Carina angle measurements for diagnosis of patent ductus arteriosus in preterm infants. Neonatology 2010;99:224-230.

5 Sehgal A, McNamara PJ: Does echocardiography facilitate determination of hemodynamic significance attributable to the ductus arteriosus? Eur J Pediatr 2009;168:907-914.

6 Sehgal A, Coombs P, Tan K, McNamara PJ: Spectral Doppler waveforms in systemic arteries and physiological significance of a patent ductus arteriosus. J Perinatol 2011;31: 150-156.

7 Keating P, Verhagen E, van Hoften J, ter Horst H, Bos AF: Effect of indomethacin infused over $30 \mathrm{~min}$ on cerebral fractional tissue oxygen extraction in preterm newborns with a patent ductus arteriosus. Neonatology 2010;98:232-237.
8 Czernik C, Lemmer J, Metze B, Koehne PS, Mueller C, Obladen M: B-type natriuretic peptide to predict ductus intervention in infants $<28$ weeks. Pediatr Res 2008;64:286290.

9 Chen S, Tacy T, Clyman R: How useful are B-type natriuretic peptide measurements for monitoring changes in patent ductus arteriosus shunt magnitude? J Perinatol 2010;30: 780-785.

10 Holmstrom H, Hall C, Thaulow E: Plasma levels of natriuretic peptides and hemodynamic assessment of patent ductus arteriosus in preterm infants. Acta Paediatr 2001; 90:184-191.

11 Gao Y, Raj JU: Regulation of the pulmonary circulation in the fetus and newborn. Physiol Rev 2010;90:1291-1335.

12 Zanardo V, Vedovato S, Lago P, Trevisanuto D, Favaro F, Faggian D, Plebani M: Urinary ET-1, AVP and sodium in premature infants treated with indomethacin and ibuprofen for patent ductus arteriosus. Pediatr Nephrol 2005;20:1552-1556.

13 Zanardo V, Vedovato S, Chiozza L, Faggian D, Favaro F, Trevisanuto D: Pharmacological closure of patent ductus arteriosus: effects on pulse pressure and on endothelin-1 and vasopressin excretion. Am J Perinatol 2008;25: 353-358.
14 Papassotiriou J, Morgenthaler NG, Struck J, Alonso C, Bergmann A: Immunoluminometric assay for measurement of the C-terminal endothelin-1 precursor fragment in human plasma. Clin Chem 2006;52:11441151.

15 Miguel D, Prieto B, Costa M, Coto D, Alvarez FV: Cord blood plasma reference intervals for potential sepsis markers: pro-adrenomedullin, pro-endothelin, and pro-atrial natriuretic peptide. Clin Biochem 2011;44:337341.

16 Schlapbach LJ, Ersch J, Adams M, Bernet V, Bucher HU, Latal B: Impact of chorioamnionitis and preeclampsia on neurodevelopmental outcome in preterm infants below 32 weeks gestational age. Acta Paediatr 2010;99: 1504-1509.

17 Wellmann S, Benzing J, Cippa G, Admaty D, Creutzfeldt R, Mieth RA, Beinder E, Lapaire O, Morgenthaler NG, Haagen U, Szinnai G, Buhrer C, Bucher HU: High copeptin concentrations in umbilical cord blood after vaginal delivery and birth acidosis. J Clin Endocrinol Metab 2010;95:5091-5096.

18 Morgenthaler NG, Struck J, Thomas B, Bergmann A: Immunoluminometric assay for the midregion of pro-atrial natriuretic peptide in human plasma. Clin Chem 2004;50: 234-236. 
19 Karl J, Borgya A, Gallusser A, Huber E, Krueger K, Rollinger W, Schenk J: Development of a novel, N-terminal-proBNP (NTproBNP) assay with a low detection limit. Scand J Clin Lab Invest Suppl 1999;230:177181.

20 El-Khuffash AF, Slevin M, McNamara PJ, Molloy EJ: Troponin T, N-terminal pro natriuretic peptide and a patent ductus arteriosus scoring system predict death before discharge or neurodevelopmental outcome at 2 years in preterm infants. Arch Dis Child Fetal Neonatal Ed 2011;96:F133-F137.
21 Benitz WE: Treatment of persistent patent ductus arteriosus in preterm infants: time to accept the null hypothesis? J Perinatol 2010; 30:241-252.

22 Mir TS, Laux R, Hellwege HH, Liedke B, Heinze C, von Buelow H, Laer S, Weil J: Plasma concentrations of aminoterminal pro atrial natriuretic peptide and aminoterminal pro brain natriuretic peptide in healthy neonates: marked and rapid increase after birth Pediatrics 2003;112:896-899.

23 Yoshibayashi M, Kamiya T, Saito Y, Nakao K, Nishioka K, Temma S, Itoh H, Shirakami G, Matsuo H: Plasma brain natriuretic peptide concentrations in healthy children from birth to adolescence: marked and rapid increase after birth. Eur J Endocrinol 1995;133: 207-209.
24 Chan D, Ng LL: Biomarkers in acute myocardial infarction. BMC Med 2010;8:34.

25 Jankowska EA, Filippatos GS, von Haehling S, Papassotiriou J, Morgenthaler NG, Cicoira M, Schefold JC, Rozentryt P, Ponikowska B, Doehner W, Banasiak W, Hartmann O, Struck J, Bergmann A, Anker SD, Ponikowski P: Identification of chronic heart failure patients with a high 12 -month mortality risk using biomarkers including plasma C-terminal pro-endothelin-1. PLoS One 2011; 6:e14506. 